\title{
Efforts to improve carrier mobility in radio frequency sputtered aluminum doped zinc oxide films
}

\author{
C. Agashe, O. Kluth, ${ }^{\text {a) }}$ J. Hüpkes, U. Zastrow, and B. Rech \\ Institute of Photovoltaics, Forschungszentrum Jülich GmbH, D-52425 Jülich, Germany \\ M. Wuttig \\ 1. Physikalisches Institut der RWTH Aachen, D-52056 Aachen, Germany
}

(Received 25 August 2003; accepted 24 November 2003)

\begin{abstract}
This study addresses the electrical and optical properties of radio frequency magnetron sputtered aluminum doped zinc oxide ( $\mathrm{ZnO}: \mathrm{Al})$ films. The main focus was on the improvement in carrier mobility $\mu$ to achieve simultaneously high transparency for visible and particularly near-infrared light and low resistivity. The influence of $\mathrm{Al}$ concentration in the target, film thickness, sputter power, deposition pressure, and substrate temperature on material properties was investigated. The structural, compositional, electrical and optical properties were studied using x-ray diffraction, secondary ion mass spectrometry (SIMS), room temperature Hall effect measurements and spectral photometry, respectively. All $\mathrm{ZnO}: \mathrm{Al}$ films were polycrystalline and preferentially oriented along [002]. The grain size along the direction of growth increased with higher Al doping and with increasing film thickness. The SIMS measurements revealed that the Al concentration in the film was nearly the same as in the target. Carrier concentration $N$ and mobility $\mu$ are determined by the target $\mathrm{Al}$ concentration. In addition $\mu$ is influenced by the film thickness and the sputter pressure. For each $\mathrm{Al}$ concentration, the highest $\mu$ was generally observed at low deposition pressures. By using a target with low $\mathrm{Al}_{2} \mathrm{O}_{3}$ concentration of $0.5 \mathrm{wt} \%, \mu$ could be improved up to $44.2 \mathrm{~cm}^{2} / \mathrm{V} \mathrm{s}$ while maintaining the electrical resistivity $\rho$ as low as $3.8 \times 10^{-4} \Omega \mathrm{cm}$. For these films the transparency in the near-infrared wavelength range strongly improved which makes them particularly interesting for the application in optoelectronic devices like thin-film solar cells. The $\mu-N$ dependence for films deposited under diverse conditions was studied to identify a practical limit for $\mu$. (C) 2004 American Institute of Physics. [DOI: 10.1063/1.1641524]
\end{abstract}

\section{INTRODUCTION}

Transparent conducting oxides (TCOs) possess a wide range of applications in a variety of optoelectronic devices such as flat-panel displays ${ }^{1}$ or thin-film solar cells. ${ }^{2-3}$ Most TCOs are based on tin oxide $\left(\mathrm{SnO}_{2}\right)$, indium tin oxide $\left(\mathrm{In}_{2} \mathrm{O}_{3}\right)$, zinc oxide $(\mathrm{ZnO})$, and their mixed compounds, and are deposited by different physical and chemical techniques. $^{4,5}$ In recent years, magnetron sputtered $\mathrm{ZnO}$ based films like $\mathrm{ZnO}$ :Al have become particularly interesting because of their surface texturability, which is needed to introduce light trapping when using them as a front contact in silicon thin film solar cells. ${ }^{2,6}$ They also form a standard front contact in copper indium gallium selenide (CIGS) thin-film solar cells. ${ }^{3}$ In addition, $\mathrm{ZnO}$ films promise lower production costs than ITO films due to lower target costs. The resistivity $\rho$ of $\mathrm{ZnO}$ :Al films can be controlled by nonstoichiometry as well as by extrinsic doping, and can be decreased up to the semimetallic regime by increasing the carrier concentration $N$ up to $1.5 \times 10^{21} \mathrm{~cm}^{-3} .7,8$ However, an undesired consequence of having such high $N$ is that it considerably increases the free carrier absorption in the near-infrared range. This adversely affects the application in thin-film solar cells

\footnotetext{
a) Author to whom correspondence should be addressed; electronic mail: o.kluth@fz-juelich.de
}

with microcrystalline silicon absorber layers, where a high optical transmission is required for the wavelength range between 400 and $1100 \mathrm{~nm}$.

Attempts to simultaneously optimize the electrical and optical properties of sputtered $\mathrm{ZnO}$ films have been performed by several researchers applying different dopants and doping concentrations. ${ }^{8}$ However, in most cases either the doping concentration was varied or the deposition parameters were optimized for a fixed doping concentration. ${ }^{5,8}$ During the past few years, optical and structural properties of radio frequency (rf) sputtered $\mathrm{ZnO}: \mathrm{Al}$ films were optimized in our group for the application in thin-film silicon solar cells, using a constant target doping concentration $\left(\mathrm{Al}_{2} \mathrm{O}_{3}: \mathrm{ZnO}\right.$ weight ratio) of $2 \mathrm{wt} \%{ }^{2,9,10}$ Highly transparent films with low resistivity $\left(\rho<3 \times 10^{-4} \Omega \mathrm{cm}\right)$ were obtained at low sputter pressures. A more effective use of $\mathrm{ZnO}: \mathrm{Al}$ films as a front contact in microcrystalline silicon solar cells requires an increased transparency in the near-infrared region while maintaining a low resistivity (see, e.g., Ref. 6). An interdependence of the electro-optical properties of $\mathrm{TCOs}^{5}$ then suggests that this can be directly achieved by improving the carrier mobility $\mu$.

Hence, the aim of the present work on rf sputtered $\mathrm{ZnO}: \mathrm{Al}$ films was to gain a deeper understanding of the relationship between different sputter process conditions and the resulting film properties to improve $\mu$ as much as pos- 
sible. The influence of target $\mathrm{Al}$ concentration, film thickness, total pressure, substrate temperature, and sputter power on the electrical properties was investigated in detail. In addition, the optical, structural, and compositional properties of selected films were characterized. Our efforts to improve the carrier mobility are discussed in the light of the TCO mobility limit suggested recently in the literature.

\section{EXPERIMENTAL PROCEDURE}

$\mathrm{ZnO}: \mathrm{Al}$ films were deposited in a high vacuum sputtering system (Lesker Inc., USA 6-in.-diameter cathode) with a base pressure of $\sim 1 \times 10^{-7}$ Torr. $\mathrm{rf}$ magnetron sputtering was used to deposit the films on Corning 1737 glass substrates with a target-substrate separation of $80 \mathrm{~mm}$. Al doping in the films was varied using ceramic targets with different weight ratio of $\mathrm{Al}_{2} \mathrm{O}_{3}$ and $\mathrm{ZnO}$. The concentration of $\mathrm{Al}_{2} \mathrm{O}_{3}$ in the target is henceforth referred to as TAC. Films were deposited in different sets to study the effect of particular parameters. Film thickness was measured using a surface profiler (Dektak, Veeco Instruments). For electrical properties, room temperature Hall effect measurements were performed using a Keithley 926 Hall setup. Transmission and reflection measurements were done on a Perkin Elmer spectrometer in the wavelength range $300-2050 \mathrm{~nm}$. The optical gap was determined from plots of the square of the absorption coefficient $\alpha^{2}$ against the photon energy $h \nu$. Structural properties such as grain orientation and grain size were studied for characteristic films using $\mathrm{x}$-ray diffraction (Philips $\mathrm{x}$-ray diffractometer) with $\theta-2 \theta$ curves in the range $20^{\circ}-80^{\circ}$. The full width at half maximum (FWHM) for the prominent (002) peak was used as a measure of grain size along [002]. Note, that the FWHM is also influenced by stress in the films. Such an effect was not investigated in the present study and could therefore not be taken into account. The quantitative analysis of $\mathrm{Al}$ concentration in the $\mathrm{ZnO}: \mathrm{Al}$ films was done using secondary ion mass spectrometry on a Quadrupol SIMS ATOMIKA 4000 instrument. $6 \mathrm{keV} \mathrm{Cs}{ }^{+}$ ions at oblique angle of incidence were used for primary bombardment and secondary $\mathrm{CsAl}^{+}, \mathrm{CsZn}^{+}$, and $\mathrm{CsO}^{+}$ molecule ions were detected. Quantification of the $\mathrm{Al}$ incorporation in the films was achieved using relative sensitivity factors determined via SIMS analysis of $200 \mathrm{keV}$, $2 \times 10^{16} \mathrm{~cm}^{-2} \mathrm{Al}$ implantation in nominally undoped, polycrystalline $\mathrm{ZnO}$.

\section{RESULTS AND DISCUSSION}

The films were deposited in different sets where specific parameters were varied at a time. The deposition parameters with their range of variation are given in Table I. The films of Set 1 were deposited to investigate the effect of TAC on the thickness dependence of the electrical properties. These films were prepared at low sputter pressure and substrate temperature. The feasibility of using low TAC was checked in this set. In the second set of experiments (Table I, Set 2), the role of sputter pressure for a low TAC of $0.5 \mathrm{wt} \%$ was studied at two characteristic substrate temperatures. These results led to a further improvement in $\mu$ by optimizing deposition pressure and substrate temperature. For these two sets it was
TABLE I. Deposition parameters target doping concentration TAC $\left(\mathrm{Al}_{2} \mathrm{O}_{3}: \mathrm{ZnO}\right.$ wt $\left.\%\right)$, sputter power $P_{w}$, substrate temperature $T_{s}$, sputter pressure $p_{s}$, deposition time $t_{d}$, Ar to $1 \% \mathrm{O}_{2}$ in Ar flow ratio and film thickness for different samples.

\begin{tabular}{lcccc}
\hline \hline & & & \multicolumn{2}{c}{ Set 3 } \\
\cline { 4 - 5 } Parameter & Set 1 & Set 2 & Series A & Series B \\
\hline TAC $\left(\mathrm{Al}_{2} \mathrm{O}_{3}: \mathrm{ZnO}\right.$ wt $\left.\%\right)$ & $0.5,1,2,4$ & 0.5 & 1 & 1 \\
$P_{w}(\mathrm{~W})$ & 225 & 225 & $100-400$ & $100-400$ \\
$T_{s}\left({ }^{\circ} \mathrm{C}\right)$ & 100 & 100,330 & 100 & 100 \\
$p_{s}(\mathrm{mTorr})$ & 2 & $0.3-30$ & 2 & 2 \\
$t_{d}(\mathrm{~min})$ & $3.5-45$ & 40 & $13-63$ & $3.6-27$ \\
Ar: $1 \% \mathrm{O}_{2}$ in $\mathrm{Ar}(\mathrm{sccm})$ & $7: 0.1$ & $7: 0$ & $7: 0.1$ & $7: 0.1$ \\
Thickness $(\mathrm{nm})$ & not fixed & not fixed & 650 & 200 \\
\hline \hline
\end{tabular}

observed that different deposition parameters and TAC resulted in different growth rates. To investigate whether the film properties contained any effect of growth rate in addition to that of a specific deposition parameter we studied the influence of growth rate by systematically varying the $\mathrm{rf}$ power (Table I, Set 3). rf power was selected to study this aspect because it does not lead to any major change in the compositional and structural film properties. ${ }^{8}$

The results are discussed in the following sections. Section III A describes the results on the relationship between deposition parameters and electrical, structural, and compositional properties. Section III B deals with the improvement in optical properties by the optimization of $\mu$ and $N$ through TAC and substrate temperature. Section III C contains a discussion of the experimental limit in the maximum achievable mobility with respect to the carrier concentration.

\section{A. Deposition parameters and material properties 1. Effect of film thickness for different target Al concentration (TAC): Electrical and structural properties}

The relationship between film thickness and electrical properties was studied for films deposited using different TAC of $0.5,1,2$, and $4 \mathrm{wt} \%$. Table I, Set 1 describes the detailed deposition conditions. Films of increasing thickness in a range of $70-1400 \mathrm{~nm}$ were deposited by varying the deposition time.

Figure 1 shows the electrical properties of these films. As seen from Fig. 1(a), the lowest resistivity was obtained for films with a TAC of $2 \mathrm{wt} \%$. In this case, $\rho<4 \times 10^{-4} \Omega \mathrm{cm}$ was achieved over a wide range of film thickness $(200-1000 \mathrm{~nm})$. Upon decreasing TAC down to 1 and $0.5 \mathrm{wt} \%, \rho$ increased in the entire range of film thickness, but more significantly for thinner films. The minimum resistivities for films with a low TAC ( 1 and $0.5 \mathrm{wt} \%)$ are obtained for film thicknesses above $1000 \mathrm{~nm}$. Furthermore, in the case of $0.5 \mathrm{wt} \%$ TAC no saturation of $\rho$ is observed up to the highest investigated film thickness of $1300 \mathrm{~nm}$. For $4 \mathrm{wt} \%$ TAC, the resistivity was quite high. Figures 1(b) and 1 (c) give more insight into the relationship between TAC and the electrical properties $N$ and $\mu$. While $N$ showed an almost linear dependence on TAC for $0.5,1$, and $2 \mathrm{wt} \%$ [Fig. 1(b)], it exhibits only a slight dependence on film thickness. Hence, the thickness dependence of $\rho$ was mainly determined by that 

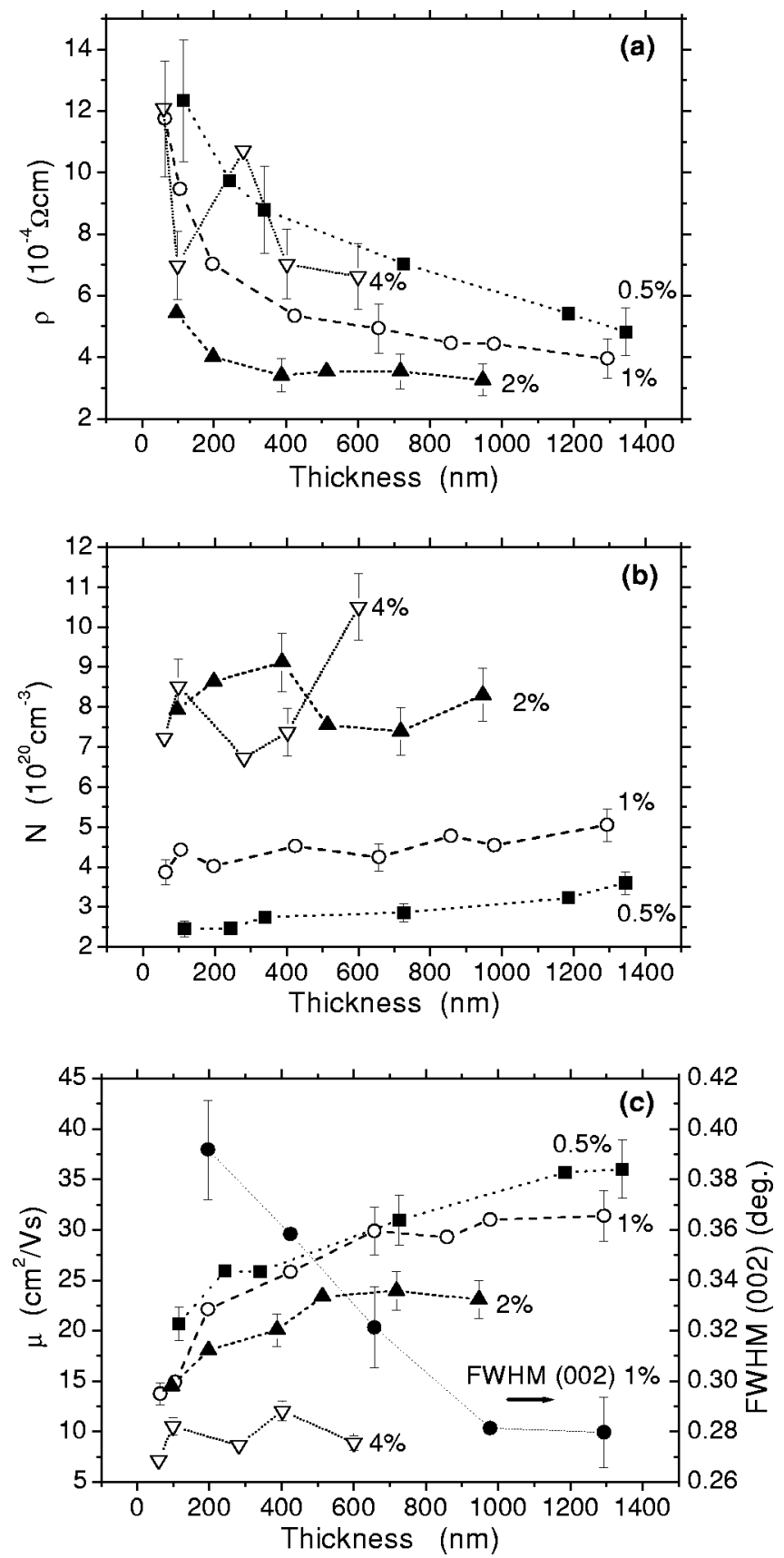

FIG. 1. Resistivity $\rho$ (a), carrier concentration $N$ (b) and mobility $\mu$ (c) of differently doped $\mathrm{ZnO}: \mathrm{Al}$ films (TAC-wt $\%$ ) as a function of film thickness; (c) also contains the FWHM of the XRD (002) peak for the $1 \% \mathrm{Al}$ doped $\mathrm{ZnO}: \mathrm{Al}$ films as a measure of the grain size along [002] (growth direction).

of $\mu$. The corresponding carrier mobility improved with decreasing TAC as well as with increasing film thickness. As a consequence, for $0.5 \mathrm{wt} \%$ TAC films, $\mu$ could be improved up to $\sim 36 \mathrm{~cm}^{2} / \mathrm{V}$ s for film thicknesses above $1000 \mathrm{~nm}$. The $\mathrm{x}$-ray diffraction (XRD) $\theta$-2 $\theta$ measurements indicated that all films were highly $c$-axis oriented. Our previous investigation of 2 wt \% TAC films using XRD pole figures is consistent with these results. ${ }^{10}$ The thickness dependence of the FWHM of the (002) peak as shown in Fig. 1(c) for the $1 \mathrm{wt} \%$ TAC series indicates that the grain size along the direction of growth has increased for thicker films. Such an increase will favorably contribute to the observed increase in $\mu$ with thick-
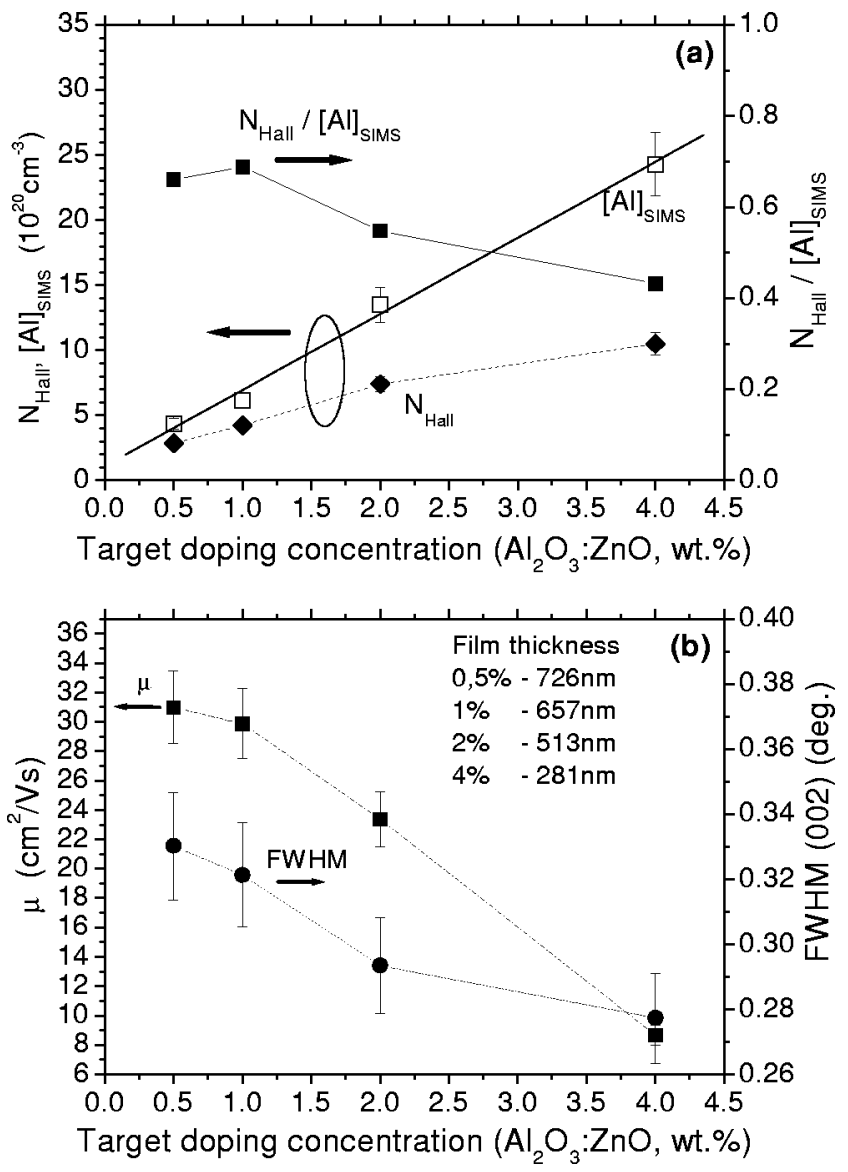

FIG. 2. (a): Al content [Al $]_{\text {SIMS }}$ determined with SIMS, $N_{\text {Hall }}$ obtained from Hall measurements and $N_{\text {Hall }} /[\mathrm{Al}]_{\text {SIMS }}$ as a function of target doping concentration. (b) The dependence of mobility $\mu$ and the full width at half maximum (FWHM) of the XRD (002) peak on the target doping concentration for films with different thickness.

ness. A higher resistivity obtained for $4 \mathrm{wt} \%$ TAC is due to the low mobility, which is probably caused by an increased incorporation of suboxides of $\mathrm{Al}-\mathrm{O}$, either in $\mathrm{Al}_{2} \mathrm{O}_{3}$ form or some intermediate. Such an effect has been proposed by other researchers in the case of heavily doped $\mathrm{ZnO}: \mathrm{Al}$ films. ${ }^{8,11}$ This aspect is further discussed in Sec. III A 2. The experimental data presented here clearly show that $\mu$ can be significantly improved and $N$ lowered by reducing the TAC to $0.5 \mathrm{wt} \%$ while still retaining a low resistivity. At low TAC, the electrical film properties remarkably improve with increasing film thickness, which can be mainly attributed to the increase in carrier mobility $\mu$. However, the overall lowest resistivity was obtained using a TAC of $2 \mathrm{wt} \%$, which was due to the high carrier concentration.

\section{Effect of TAC: Electrical, structural, and compositional properties}

The $\mathrm{Al}$ concentration in the films $[\mathrm{Al}]_{\text {SIMS }}$ was derived from SIMS measurements and is plotted as a function of TAC in Fig. 2(a). Films grown with identical deposition conditions but different TAC were selected for this study. The Al content $[\mathrm{Al}]_{\text {SIMS }}$ in the film increased linearly with TAC. For comparison, $N_{\text {Hall }}$ from Hall data and the ratio $N_{\text {Hall }} /[\mathrm{Al}]_{\text {SIMS }}$ are also depicted in Fig 2(a). These data ob- 
viously show that for the low TAC of 0.5 and $1 \mathrm{wt} \%$, the doping was largely effective while for higher TAC up to 4 wt $\%$, the effectiveness of doping decreased continuously thereby indicating that an increasing extent of the built-in Al was electrically nonactive. It should also be noted here that aluminum oxide $\mathrm{Al}_{2} \mathrm{O}_{3}$ has a higher enthalpy of formation than $\mathrm{ZnO}$. Hence, increasing TAC will probably favor the formation of aluminum oxide to an increasing extent. This can lead to additional oxygen vacancies in the $\mathrm{ZnO}$ lattice, which would counteract the effect of decreasing $N$ by $\mathrm{Al}_{2} \mathrm{O}_{3}$ formation.

In Fig. 2(b), the corresponding carrier mobility and FWHM (002) are shown for this doping series. With increasing TAC a reduction in FWHM (002) and also a decrease in mobility $\mu$ is observed. Since the thickness of the films decreases with TAC, one would expect an increase of FWHM for these films from the thickness dependence shown in Fig. $1(\mathrm{c})$. The opposite is the case, which means that the thickness effect on the FWHM is overcompensated by the strong effect of the $\mathrm{Al}$ incorporation, which leads to a promotion of the crystallite growth along [002].

The decrease of $\mu$ seen in Fig. 2(b) is also caused by the increased TAC rather than by an effect of the film thickness. Note, that the chosen film thickness for each TAC in Fig. 2(b) is already in the thickness region where the mobility is almost independent from the film thickness [see Fig. 1(c)]. This drop in $\mu$ with increasing TAC already shown in Fig. 1(c) can be explained by an increasing amount of scattering centers present in the films at higher TAC. These scattering centers can consist of ionized $\mathrm{Al}$ or $\mathrm{Al}_{2} \mathrm{O}_{3}$ and its suboxides, which is indicated by the decrease of the ratio $N_{\mathrm{Hall}} /[\mathrm{Al}]_{\mathrm{SIMS}}$ seen in Fig. 2(a). Both will cause additional scattering of the charge carriers, which adversely affects the carrier transport.

\section{Effect of sputter pressure and substrate temperature-electrical properties}

To further improve the mobility for $0.5 \mathrm{wt} \%$ films, the effects of sputter pressure and deposition temperature were investigated. The deposition conditions are described in Table I, Set 2. Figure 3 shows the pressure dependence of $\rho$, $N$, and $\mu$ for substrate temperatures of 100 and $330{ }^{\circ} \mathrm{C}$. The film thickness varied between 800 and $1350 \mathrm{~nm}$ due to the pressure dependence of the deposition rate.

The resistivity $\rho$ was low for a sputter pressure up to 10 mTorr [see Fig. 3(a)]. At higher pressures, $\rho$ strongly increased for both substrate temperatures. A similar dependence of $\rho$ on the pressure was observed in our former study for $2 \mathrm{wt} \%$ TAC both with rf and reactive direct current (dc) sputtering. ${ }^{10}$ Increasing the substrate temperature to $330^{\circ} \mathrm{C}$ reduced $\rho$ in the entire pressure range. Figure 3(b) shows that $N$ varied not more than by a factor of two and remained nearly constant in the pressure range of $0.3-30$ mTorr at $330^{\circ} \mathrm{C}$. For a substrate temperature of $100^{\circ} \mathrm{C}$ the mobility reached $39 \mathrm{~cm}^{2} / \mathrm{V} \mathrm{s}$ in the pressure range of $1-2 \mathrm{mTorr}$, followed by a significant drop to $4 \mathrm{~cm}^{2} / \mathrm{Vs}$ for a higher pressure of 30 mTorr. A minimum resistivity of $4.3 \times 10^{-4} \Omega \mathrm{cm}$ and maximum mobility of $41 \mathrm{~cm}^{2} / \mathrm{V} \mathrm{s}$ could be obtained using a substrate temperature of $330^{\circ} \mathrm{C}$.
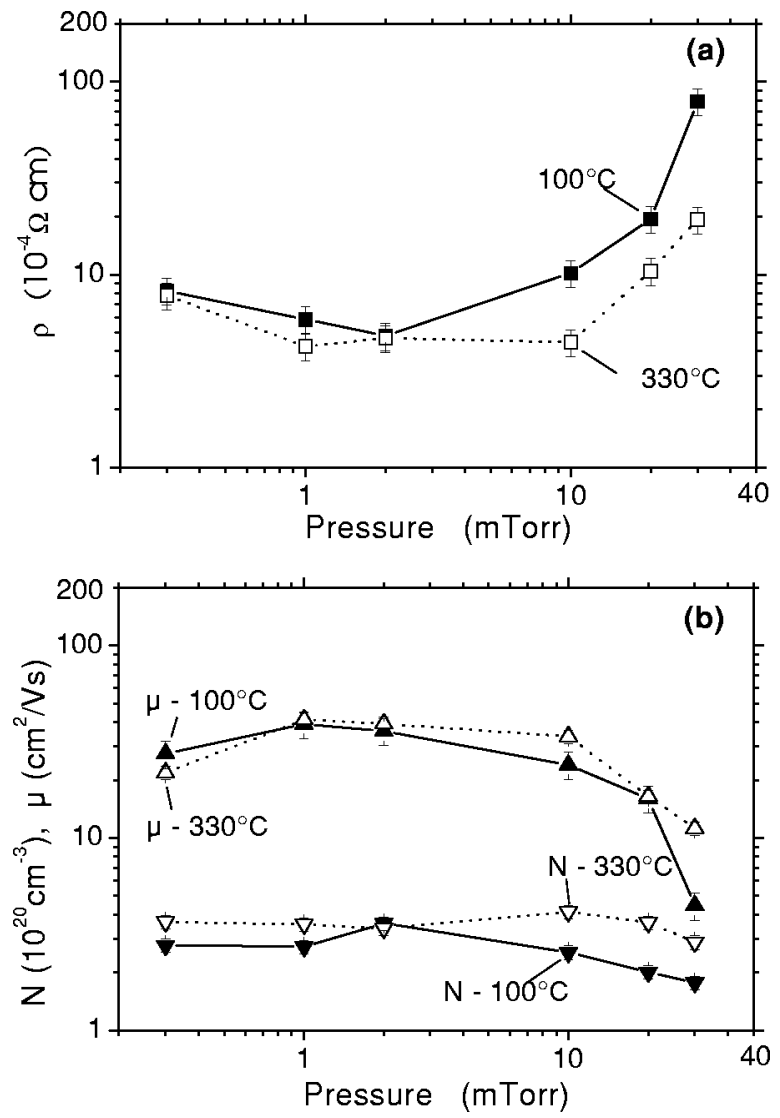

FIG. 3. Resistivity $\rho$ (a), carrier concentration $N$ and mobility $\mu$ (b) for 0.5 wt $\%$ TAC and $800-1350 \mathrm{~nm}$ thick films as a function of sputter pressure at different deposition temperatures.

Figure 3 also shows that at increased substrate temperature, a higher $\mu$ (and lower $\rho$ ) could be obtained over a wider pressure range.

In summary, by adjusting sputter pressure and substrate temperature, a slight improvement in the electrical properties of the $0.5 \mathrm{wt} \%$ TAC films was observed. By further tuning of the deposition parameters, the maximum mobility could be increased up to $44.2 \mathrm{~cm}^{2} / \mathrm{V} \mathrm{s}$, shifting the minimum resistivity $\rho$ to $3.7 \times 10^{-4} \Omega \mathrm{cm}$ for a $690 \mathrm{~nm}$ thick film.

\section{Effect of growth rate-electrical properties}

The respective variations in TAC, sputter pressure and substrate temperature discussed in Secs. III A 1 and III A 3 had a major influence on the growth rate, in spite of applying the same rf power. For example, upon increasing the TAC from 0.5 to $4 \mathrm{wt} \%$, the growth rate decreased from 35 to $15 \mathrm{~nm} / \mathrm{min}$. To separate the effects of growth rate from those of the deposition parameters reported in Secs. III A 1 and III A 3, a study of films of controlled thickness but obtained using different growth rates was undertaken. The growth rate was controlled using a sputter power between 100 and $400 \mathrm{~W}$. For details of experimental conditions see Table I, Set 3. The deposition time was adjusted for a particular growth rate to obtain a film thickness of $\sim 650 \mathrm{~nm}$ (Series A) and of $\sim 200 \mathrm{~nm}$ (Series B). A TAC of $1 \mathrm{wt} \%$ was chosen. The dependence of $\mu$ on the growth rate is given in Fig. 4 for both series of films. The carrier mobility was al- 


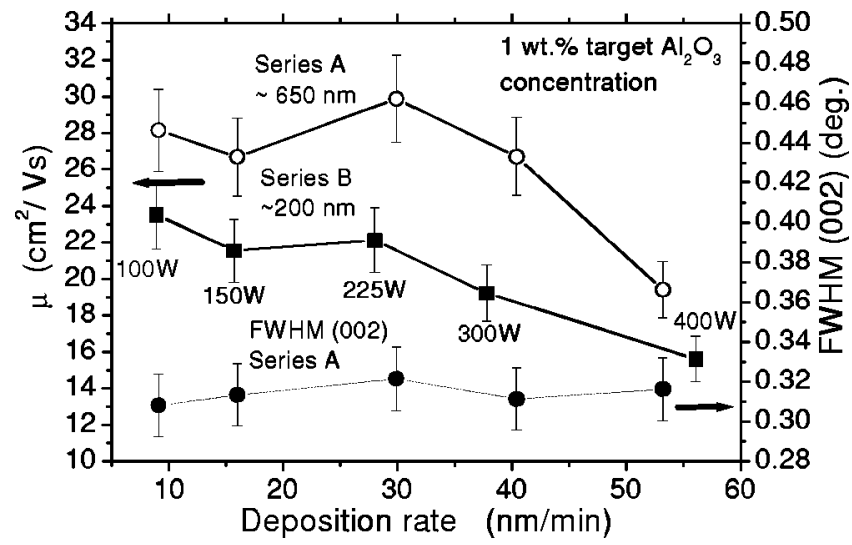

FIG. 4. Dependence of carrier mobility on deposition rate for films with a thickness of $\sim 650$ and $\sim 200 \mathrm{~nm}$. Sputter parameters are given in Table I, set 3. In addition, for series A the FWHM of the XRD (002) peak is shown.

most constant up to a deposition rate of $40 \mathrm{~nm} / \mathrm{min}$ for 650 $\mathrm{nm}$ film thickness and decreased only at even higher growth rates. For the $200 \mathrm{~nm}$ thick films (series B) $\mu$ is slightly reduced with increasing deposition rate. The thicker films always exhibited a higher mobility, which could be attributed to the reduced prominence of early growth effects in these films as compared to the thinner films. The resistivity and the carrier concentration of series A and B were in the range of $\rho=4-7 \times 10^{-4} \Omega \mathrm{cm}$ and $N=4-6.5 \times 10^{20} \mathrm{~cm}^{-3}$.

The XRD study of series A films revealed that the FWHM (002), which corresponds to the grain size in growth direction, was not affected by the growth rate. Similar results were obtained by Igasaki and Saito, who reported that an increase in growth rate (by varying sputter power) up to 30 $\mathrm{nm} / \mathrm{min}$ did not significantly change the FWHM (002). ${ }^{12}$ The invariance of the FWHM (002) may be the reason that $\mu$ is only slightly affected in this range of growth rates. This suggests that owing to the natural tendency of $\mathrm{ZnO}$ based films to grow along [002], ${ }^{13}$ the growth rate may have a less influential role in the growth process.

In brief, the best possible bulk properties could be obtained for a film thickness above $650 \mathrm{~nm}$ and applying a moderate sputter power corresponding to growth rates of up to $40 \mathrm{~nm} / \mathrm{min}$. Since all $\mathrm{ZnO}: \mathrm{Al}$ films except those in this section were deposited with growth rates below $40 \mathrm{~nm} / \mathrm{min}$, we conclude that our results in previous sections are not dominated by growth rate related effects.

\section{B. Optical properties}

Several characteristic films with a variation of TAC and substrate temperature were selected to study the optical properties. The transmittance and reflectance of differently doped films deposited at a substrate temperature of $T_{s}=100^{\circ} \mathrm{C}$ and having a comparable film thickness $(600-725 \mathrm{~nm})$ are given in Fig. 5(a). Additionally, Fig. 5(b) shows the optical properties for 0.5 and $4 \mathrm{wt} \%$ TAC films with a thickness of $580-725 \mathrm{~nm}$ deposited at $330^{\circ} \mathrm{C}$. The step around $870 \mathrm{~nm}$ is identified as a measurement artifact caused by the change of the detector in the spectrometer. So the measurements in the wavelength range $800-950 \mathrm{~nm}$ contain some error. Note that
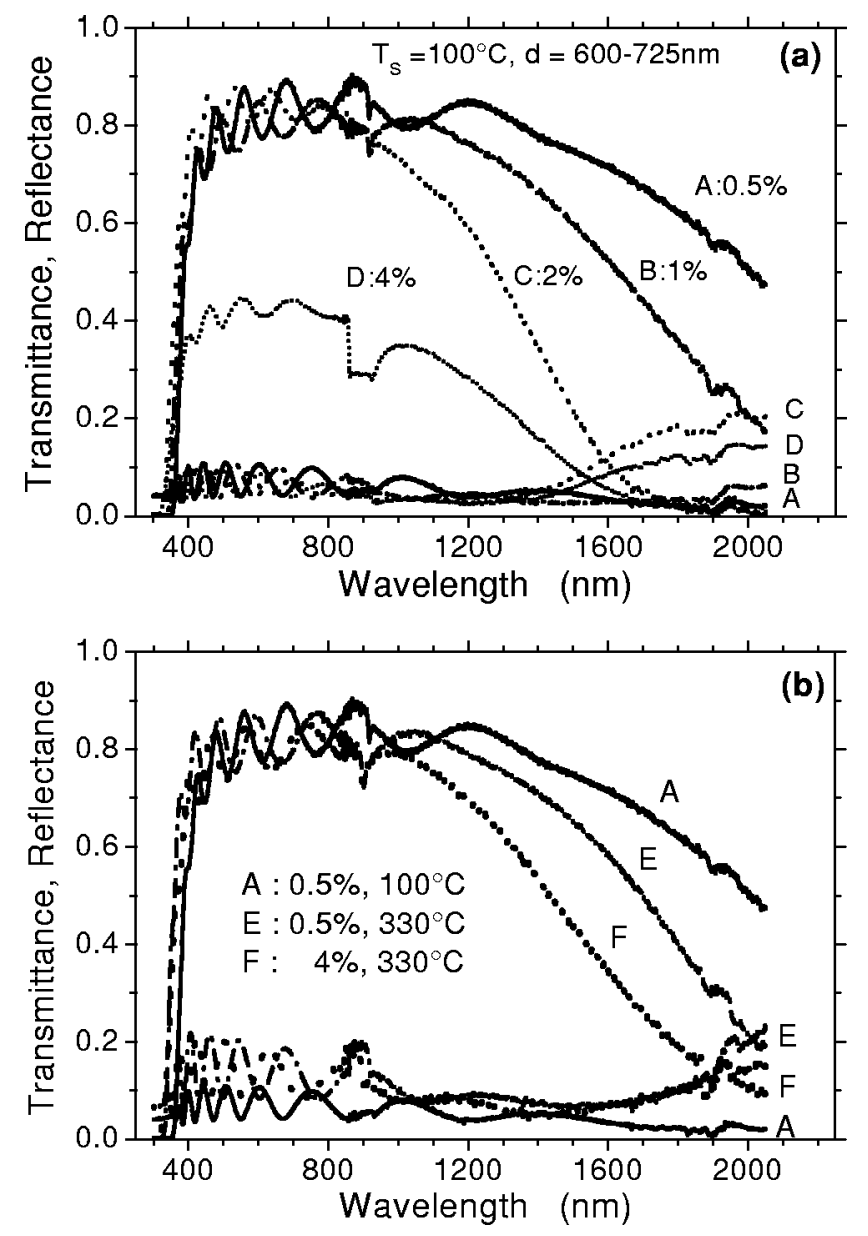

FIG. 5. (a) Transmittance and reflectance of differently doped films $\left(T_{S}\right.$ $=100{ }^{\circ} \mathrm{C}$, film thickness $d=600-725 \mathrm{~nm}$ ). The steps in the spectra at around $870 \mathrm{~nm}$ are artifacts caused by the detector change in the spectrometer. (b) Influence of the target doping concentration and the substrate temperature on the transmittance and reflectance of $\mathrm{ZnO}: \mathrm{Al}$ films with thickness $d=580-725 \mathrm{~nm}$.

outside this wavelength range the accuracy of the measurement is good. The variation in optical gap for these films is given in Fig. 6. The electronic transport parameters of all these films are summarized in Table II for reference.

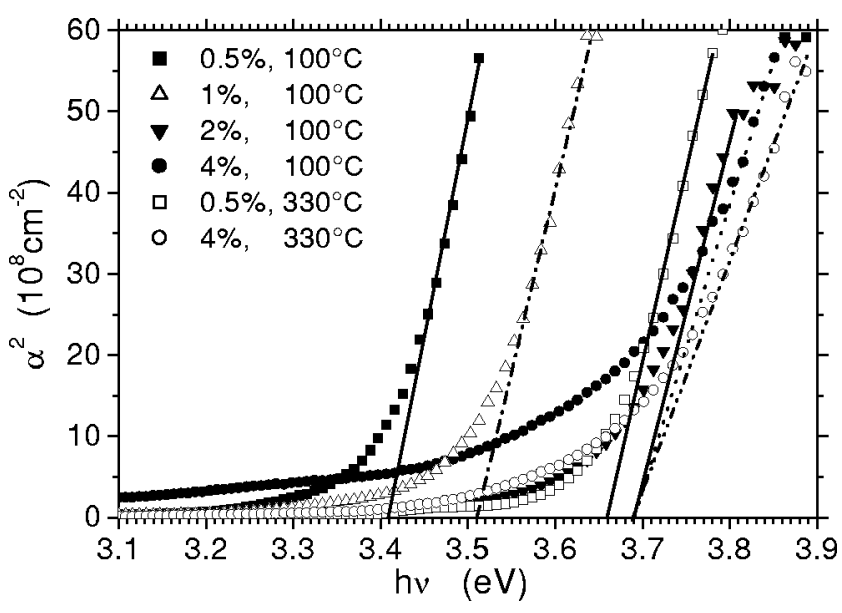

FIG. 6. Square of the absorption coefficient $\alpha^{2}$ as a function of the incident photon energy $h \nu$ for the films shown in Figs. 5(a) and 5(b). 
TABLE II. Electronic transport parameters sheet resistance $R_{s h}$, resistivity $\rho$, carrier concentration $N$, mobility $\mu$, and the optical gap for $\mathrm{ZnO}: \mathrm{Al}$ films deposited with different target doping concentration (TAC) and deposition temperature. (Optical data of these films are shown in Figs. 5 and 6.)

\begin{tabular}{|c|c|c|c|c|c|c|c|}
\hline $\begin{array}{l}\text { TAC } \\
\left(\mathrm{Al}_{2} \mathrm{O}_{3}: \mathrm{ZnO}\right. \\
\text { wt \%) }\end{array}$ & $\begin{array}{c}T_{s} \\
\left({ }^{\circ} \mathrm{C}\right)\end{array}$ & $\begin{array}{l}\text { Film } \\
\text { thickness } \\
(\mathrm{nm})\end{array}$ & $\begin{array}{c}R_{s h} \\
\text { 4-probe } \\
(\Omega / \text { sq. })\end{array}$ & $\begin{array}{c}\rho \\
\times 10^{-4} \\
(\Omega \mathrm{cm})\end{array}$ & $\begin{array}{c}N \\
\times 10^{20} \\
\left(\mathrm{~cm}^{-3}\right)\end{array}$ & $\begin{array}{c}\mu \\
\left(\mathrm{cm}^{2} / \mathrm{V} \mathrm{s}\right)\end{array}$ & $\begin{array}{l}\text { Optical } \\
\text { gap } \\
(\mathrm{eV})\end{array}$ \\
\hline 0.5 & 100 & 726 & 16 & 7 & 2.9 & 31 & 3.41 \\
\hline 1 & 100 & 657 & 10.1 & 4.9 & 4.2 & 29.9 & 3.51 \\
\hline 2 & 100 & 718 & 7.5 & 3.5 & 7.4 & 24 & 3.69 \\
\hline 4 & 100 & 600 & 18 & 6.6 & 10.5 & 8.9 & 3.69 \\
\hline 0.5 & 330 & 640 & 9.6 & 4.3 & 3.6 & 41.3 & 3.66 \\
\hline 4 & 330 & 582 & 96 & 44.1 & 3.9 & 3.7 & 3.69 \\
\hline
\end{tabular}

Figure 5 clearly shows that by lowering the TAC and consequently $N$, there was a considerable improvement in the near-infrared transmission, typically up to a wavelength of $\sim 1200 \mathrm{~nm}$. The reflectance did not vary much in the range $300-1200 \mathrm{~nm}$. The widening of the optical gap as seen from Fig. 6 and Table II with increased Al concentration, follows the Burstein-Moss effect in these films. By reducing the TAC from 4 to $0.5 \mathrm{wt} \%$ and using the substrate temperature $100{ }^{\circ} \mathrm{C}$, the optical gap decreased from 3.69 to $3.41 \mathrm{eV}$. For most applications the short wavelength transmission achieved with $0.5 \mathrm{wt} \%$ is still sufficient. The 4 wt $\%$ TAC films deposited at $100{ }^{\circ} \mathrm{C}$ exhibited poor transmission of about $40 \%$ in the visible wavelength range. The $4 \mathrm{wt} \%$ films prepared at $330^{\circ} \mathrm{C}$ showed strongly improved transmission as seen in Fig. 5(b). In this figure the transmittance and reflectance of two $0.5 \mathrm{wt} \%$ films deposited at 100 and $330^{\circ} \mathrm{C}$ are given for comparison. These films possessed a considerably improved mobility $\mu$ of 31 and $41 \mathrm{~cm}^{2} / \mathrm{V} \mathrm{s}$, respectively. In fact, film $E$ deposited with $0.5 \mathrm{wt} \% \mathrm{TAC}$ and at $330^{\circ} \mathrm{C}$ shows excellent optical properties for the application in thin-film solar cells where a high transmittance from the visible to the near-infrared region is required. Film $E$ was highly transparent from 380 to $1100 \mathrm{~nm}$ and showed a low sheet resistance of $9.6 \Omega / \mathrm{sq}$. ( $\rho=4.3 \times 10^{-4} \Omega \mathrm{cm}$ ).

A detailed discussion on optical properties of TCOs was published for example by Jin et al. ${ }^{14}$ The interrelationship of the optical and electrical properties through the transport parameters was discussed in the review on TCOs by Chopra et al. ${ }^{5}$ The results presented here clearly show that the $0.5 \mathrm{wt} \%$ films deposited at higher temperature meet our requirements of (1) wide optical gap of $3.66 \mathrm{eV}$ compared to that of $2 \mathrm{wt} \%$ TAC films $(3.69 \mathrm{eV})$ deposited at $100^{\circ} \mathrm{C}$, (2) a reduction in free carrier absorption in the near-infrared range due to lowering of $N$, (3) a slightly sharper transition from high visible and near-infrared transparency towards lower transparency for higher wavelengths (caused by the higher

$\mu)$; along with a shift in the plasma wavelength to higher values [clearly evident from Figs. 5(a) and 5(b)], and (4) a low resistivity of $3-4 \times 10^{-4} \Omega \mathrm{cm}$, which is almost as low as for the routinely used $2 \mathrm{wt} \%$ films, particularly for film thicknesses above $\sim 600 \mathrm{~nm}$. This means that using a low TAC like $0.5 \mathrm{wt} \%$ could prove a preferable choice to obtain $\mathrm{ZnO}: \mathrm{Al}$ films, for the applications where a high transparency at long wavelength is required, e.g., in silicon thin-film solar cells. Note however, that for low TAC the lowest resistivity could be achieved only at higher substrate temperatures than are required for the standardly used TAC of 2 wt. \%.

\section{Experimental limit of the maximum mobility}

The focus of this study was to improve the electrical and optical properties of rf sputtered $\mathrm{ZnO}$ :Al films. Low resistivities are easily achieved by using a high TAC, which leads to high carrier concentration and thus also to high optical absorption in the spectral NIR range. In the previous sections we demonstrated that the mobility of $\mathrm{ZnO}: \mathrm{Al}$ can be increased remarkably by lowering $\mathrm{Al}$ doping down to $0.5 \mathrm{wt} \%$ and optimizing the deposition parameters such as sputter pressure, substrate temperature, and film thickness to obtain highly conductive films with improved optical transmission.

For the further discussion we compiled the $\mu-N$ data for all films deposited in this study (see Fig. 7). This included the variation in film thickness, substrate temperature, sputter power, and pressure for the films deposited with different TAC. The range of $N$ was mainly determined by the TAC and varied from $1.4 \times 10^{20}$ to $1 \times 10^{21} \mathrm{~cm}^{-3}$. The mobility also showed a variation by almost one order of magnitude depending on the deposition conditions. The overall maximum mobility of $44.2 \mathrm{~cm}^{2} / \mathrm{V} \mathrm{s}$ was achieved at a carrier concentration of $3.8 \times 10^{20} \mathrm{~cm}^{-3}$ using the lowest TAC of 0.5

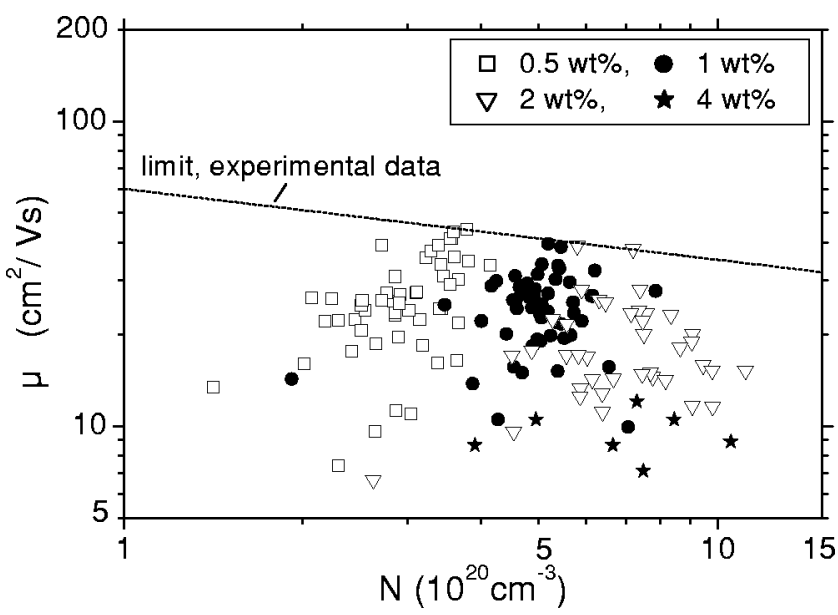

FIG. 7. $\mu-N$ dependence of $\mathrm{ZnO}: \mathrm{Al}$ films deposited under diverse conditions. Each point represents a $\mathrm{ZnO}: \mathrm{Al}$ film sputtered with a different set of deposition parameters. 
wt $\%$. The maximum mobility for a certain carrier concentration continuously decreases with increasing $N$. The dashed line in Fig. 7 shows an extrapolation of the maximum $\mu$ values in the range $N=3.8 \times 10^{20}-7.2 \times 10^{20} \mathrm{~cm}^{-3}$ obtained in this work. This extrapolation follows the power law dependence $\mu \sim N^{-1 / 4.3}$.

In recent reviews of the possible limits of electrical transport parameters in polycrystalline $\mathrm{ZnO}$ films by Ellmer ${ }^{15}$ and Minami $^{16}$ it is stated that for $N$ $=1-10 \times 10^{20} \mathrm{~cm}^{-3}$ ionized impurity scattering limits the maximum mobility. Ellmer found a power law dependence of $\mu \sim N^{-1 / 5.6}$ in the region $10^{19}<N<10^{20} \mathrm{~cm}^{-3}$ and gave a mobility limit of $40 \mathrm{~cm}^{2} / \mathrm{V} \mathrm{s}$ for $N>5 \times 10^{20} \mathrm{~cm}^{-3}$.

The $\mu-N$ dependence found in this work is comparable and the maximum mobilities achieved for $N$ $>5 \times 10^{20} \mathrm{~cm}^{-3}$ are in close vicinity to this limit of $\mu$. In a detailed study Young et al. ${ }^{17}$ determined the scattering parameter for different scattering mechanisms in the range $N$ $=1 \times 10^{19}-5 \times 10^{20} \mathrm{~cm}^{-3}$ by the four-coefficient method and found ionized impurity scattering to be the dominant scattering mechanism in $\mathrm{Al}$ doped $\mathrm{ZnO}$. According to these results the experimental limit for the maximum mobility found in our study is mainly determined by ionized impurity scattering. However, for very high $\mathrm{Al}$ concentration (in our case $\mathrm{TAC}=4$ wt. $\%$ ), additional effects like impurity cluster scattering need to be considered. ${ }^{15}$

\section{CONCLUSIONS}

In this work, a successful attempt was made to improve the carrier mobility in rf-sputtered $\mathrm{ZnO}: \mathrm{Al}$ films. The electrical and optical film properties were found to be mainly determined by $\mathrm{Al}$ doping concentration, film thickness, sputter pressure, and substrate temperature, while growth rate and sputter power showed a comparatively small influence. SIMS results revealed that the Al incorporation into the film was linearly dependent on the target doping concentration TAC, but doping was more effective at lower TAC. Using a low TAC of $0.5 \mathrm{wt} \%$, the mobility could be improved up to $44.2 \mathrm{~cm}^{2} / \mathrm{V}$ s while maintaining the electrical resistivity $\rho$ as low as $3.7 \times 10^{-4} \Omega \mathrm{cm}$. These films showed a very low free carrier absorption and plasma frequency making them an excellent choice for the application in microcrystalline silicon thin-film solar cells where high transmittance from visible to near-infrared is required. The maximum mobility experimentally achieved for a certain carrier concentration $N$ continuously decreases with increasing $N$. The comparison with literature data implies that ionized impurity scattering is the major scattering mechanism, which limits the mobility in these optimized films.

\section{ACKNOWLEDGMENTS}

The authors thank W. Appenzeller, H. Siekmann, and G. Schöpe for extensive technical assistance. We thank J. Müller for helpful discussions. Financial support by the BMWi under Contract No. 0329854A and the BMBF under Contract No. 01SF0030 is gratefully acknowledged.

${ }^{1}$ Y. Li, G. S. Tompa, S. Liang, C. Gorla, Y. Lu, and J. Doyle, J. Vac. Sci. Technol. A 15, 1063 (1997).

${ }^{2}$ B. Rech and H. Wagner, Appl. Phys. A: Mater. Sci. Process. 69, 155 (1999).

${ }^{3}$ U. Rau, D. Braunger, and H. W. Schock, Solid State Phenom. 67-68, 409 (1999).

${ }^{4}$ T. J. Coutts, D. L. Young, X. Li, W. P. Mulligan, and X. Wu, J. Vac. Sci. Technol. A 18, 2646 (2000).

${ }^{5}$ K. L. Chopra, S. Major, and D. K. Pandya, Thin Solid Films 102, 1 (1983).

${ }^{6}$ B. Rech, O. Kluth, T. Repmann, T. Roschek, J. Springer, J. Müller, F. Finger, H. Stiebig, and H. Wagner, Sol. Energy Mater. Sol. Cells 74, 439 (2002).

${ }^{7}$ R. Gordon, MRS Bull. 25, 52 (2000).

${ }^{8}$ H. L. Hartnagel, A. L. Dawar, A. K. Jain, and C. Jagdish, in Semiconducting Transparent Thin Films (Institute of Physics, Bristol, 1995), and references therein.

${ }^{9}$ O. Kluth, A. Löffl, S. Wieder, C. Beneking, W. Appenzeller, L. Houben, B. Rech, H. Wagner, S. Hoffmann, R. Waser, J. A. A. Selvan, and H. Keppner, Proceedings of the 26th IEEE Photovoltaic Specialists Conference, Anaheim, CA (1997), p. 715.

${ }^{10}$ O. Kluth, B. Rech, L. Houben, S. Wieder, G. Schöpe, C. Beneking, H. Wagner, A. Löffl, and H. W. Schock, Thin Solid Films 351, 247 (1999).

${ }^{11}$ A. F. Aktaruzzaman, G. L. Sharma, and L. K. Malhotra, Thin Solid Films 198, 67 (1991).

${ }^{12}$ Y. Igasaki and H. Saito, J. Appl. Phys. 70, 3613 (1991).

${ }^{13}$ N. Fujimura, T. Nishihara, S. Goto, J. F. Xu, and T. Ito, J. Cryst. Growth 130, 269 (1993)

${ }^{14}$ Z.-C. Jin, I. Hamberg, and C. G. Granqvist, J. Appl. Phys. 64, 5117 (1988).

${ }^{15}$ K. Ellmer, J. Phys. D 34, 3097 (2001).

${ }^{16}$ T. Minami, MRS Bull. 25, 38 (2000).

${ }^{17}$ D. L. Young, T. J. Coutts, V. I. Kaydanov, A. S. Gilmore, and W. P. Mulligan, J. Vac. Sci. Technol. A 18, 2978 (2000). 